\title{
Refocusing on Operational Harvest Planning Model for State-Owned Forestry in Turkey
}

\author{
Mehmet Eker ${ }^{1 *}$ (D), John Sessions 2 (iD) \\ ${ }^{1}$ Isparta University of Applied Sciences, Faculty of Forestry, Isparta, Turkey \\ ${ }^{2}$ Oregon State University, College of Forestry, Corvallis, Oregon, USA
}

\begin{abstract}
The growing concerns on forest ecosystem services and sustainable management of the resources with workforce, material, and products require effective planning of forestry operations in a hierarchical level. Operational planning as a component of the hierarchy generates short-term harvest planning decisions to minimize total costs by making production and distribution decisions during all seasons. Operational harvest planning of wood harvesting has been not used in Turkish conditions. Many developments and changes in managerial and operational processes in Turkish state forestry require the right product in the right place at the right time. This indicates that it is time to use operational planning to solve the wood harvesting problem with respect to specific conditions of Turkish forestry. This study introduces a model for annual planning of harvest operations/operational harvest planning (OHARP) from stand to storage for a one-year time horizon. The article presents how the operational decisions can be optimized for selection of the most appropriate harvesting blocks, time, system, landing location, and transportation mode to provide the best balance between time and cost. The mathematical model of the planning problem was formulated with linear and mixed integer programming techniques. The data for the model comes from the forest planning units and operation systems which is combined to minimize total supply costs subject to technical, environmental and socio-economic constraints. The model was tested with the real harvesting data from a forest district in the Mediterranean Region for a one year planning horizon. The test results demonstrated that when the OHARP model was implemented in the test area and compared with the actual cost of the harvest operations realized in this area, a savings of at least $4 \%$ could be achieved by better matching appropriate harvesting systems and methods to the terrain using the OHARP methodology. When operational decisions including resource constraints were optimized, up to a $30 \%$ cost reduction could be achieved in terms of average harvesting and transportation cost.
\end{abstract}

Keywords: Operational planning, annual harvest planning, wood harvesting, optimization, AHP

\section{Introduction}

Sustainable forest management in Turkey faces many challenges for efficient utilization of forest ecosystem services. Further cost rationalizations, productivity in forest operations and enhancements of the value chain of wood procurement are necessary to overcome the probable obstacles and for sectoral competitiveness. The most effective way to improve forest operations is through comprehensive planning of all harvest activities. However, large forest areas, low productivity per hectare, dependence of local and regional forest enterprises on the state-owned forestry system, constitute an important planning problem. Turkish forest area is 22.74 Mha (million hectares) and cover roughly $29 \%$ of the surface area of the entire country, $56 \%$ of which is productive high forest. Less than $50 \%$ of the net annual increment (47.2 $\mathrm{Mm}^{3}$; million cubic meter) of the managed forests is harvested yearly. The average yield is less than $100 \mathrm{~m}^{3} /$ ha in productive and degraded standing forests on steep terrain. The annual increment is a limitation for the wood harvest potential. However, 2019, round wood harvest was 22.11 million $\mathrm{m}^{3}$ (FS, 2020). At the current harvesting levels, it is estimated that $77 \%$ of domestic demand is supplied by the sales of round wood (Eker, 2020). More than $99 \%$ of the forest area is owned by the state, which is operated by General Directorate Forestry (GDF).

Multifunctional forest management plans are prepared for each planning unit, These plans provide the harvestable compartments (blocks) in each year within a planning horizon. Harvest decisions are based on 10-year forest management plans and silvicultural prescriptions for a mid-time horizon. The harvesting capacity is estimated with respect to thinning and final felling to supply total harvested volume demanded and typically to maximize net present value, on a 10-year time span. At the temporal and spatial framework, all forest operations must be executed by forest villagers nearest to the workplace in accordance with the legal obligation, forest acts and regulations. Forest work provides vital 
economic contributions for forest villagers, around 6.97 million people living over 22.941 forest villages (FS, 2020). Wood harvesting is a monopoly operated by forest villagers and their cooperatives with 190.000300.000 members. The forestry workers often lack training and professional education.

These characteristics of state forestry, combined with basic to moderate harvesting technology (Eker, 2020), drive up costs and make domestic wood production less competitive. The wood supply chain is a multifaceted process that involves resource allocation in terms of forest, people, machines, money, and time affected by technical, environmental, ecological, social, and economic factors. Depending on the harvest decisions, wood may lose value or gain in every step throughout the entire process. Quality and quantity losses in wood products are a phenomenon frequently encountered during traditionally oriented harvest operations (Acar, 1994; Ünver Okan and Acar, 2009). Tree cutting, log skidding, and hauling operations are expensive (Şafak et al., 2019) since the physical environment is difficult and the harvest systems are not efficient.

Forest harvesting decisions and operations are organized, guided, managed, and controlled at the planning unit scale via the Chief Office of the Forest District (COFD), a local branch of GDF. Annual harvest programs for each COFD starts with the budgetary preparation efforts. At the national scale, GDF reviews the proposed budgets coming from all COFD subject to past performance and compliance with the strategic plan's objectives. Once the budget is accepted, each COFD finalizes its own program in line with the allocated budget and decides its own annual allowable cut (AAC). This hierarchical cycle is carried out for all COFD in each year, from the second half of the preceding year to the beginning of the following year. However, these harvest programs cannot describe harvesting time and scheduling of the harvest blocks and appropriate allocation of the harvesting systems within the one year time horizon. Additionally, the decisions about harvest operations; appropriate harvesting time, harvesting systems, and crew size are manually made by experienced persons using rules of thumb. There is neither annual harvest planning nor decision support mechanism/procedures to optimize harvest decisions in Turkish forestry (Eker and Acar, 2006; Eker, 2020).

Research efforts illustrate that optimizing the planning of the harvest operations can be very effective at improving the wood supply chain (Dykstra and Heinrich, 1996). Forest harvest planning is a complex process because of many different and conflicting issues. Reaching the optimal solutions has become increasingly more difficult with the forest conditions and actual forestry practices, such as societal factors in state owned forests. However, the planning approaches greatly help the managers and planners in arriving at decisions to meet the multi-objective needs. In this concept, harvest planning is generally dealt with using the hierarchical planning approach with three levels; strategic, tactical, and operational (Robak, 1984; Weintraub and Cholaky, 1991; Gunn, 1991; Epstein et al., 1999; Laroze and Greber, 1991; Martel et al., 1998; Sessions and Bettinger, 2001; Beaudoin et al., 2008). Short-term, less than 5 years, harvest planning is generally inserted into the operational planning level. But, when the scope and time frame of the harvest decisions is extended, the hierarchical level is tactical (Karlsson et al., 2002). The planning time horizon, forest area and planning objectives can change the hierarchical level of the harvest planning.

To carry out harvest operation planning, macro (10 years) and micro (1 year) level transportation planning is used based on harvesting system selection according to the physical/topographical conditions of harvesting area (Bayoğlu, 1972; Acar, 1994). In addition to the physical dimension, the economic dimension is also important. Therefore, to develop economically optimal harvest plans, mathematical-statistics methods and productivitycost analysis functions are used. But, conventional evaluation techniques connected with economic analysis are not useful for the harvest planning problem (Reimer, 1979). For that reason, operations research techniques are used as a quantitative decision support system (Oborn, 1996). A historical bibliography on operations research in forestry by Martin and Sendak (1973) referenced 45 applications of operations research (OR) techniques for forestry planning for harvesting and 28 applications for timber transport. Additionally, Schuster et al. (1993) identified many computer programs based on dynamic, linear (LP), integer (IP), and mixed integer (linear) programming (MIP), network analysis, (meta) heuristics, simulation, artificial intelligence/expert systems used modeling as well as the work of Epstein et al. (2006) and Weintraub, et al.(2007). Recently, many harvest operation planning models have been developed for the entire harvesting process or a part of the process such as logging, hauling or skyline route planning as separately (Rönnqvist et al., 1999; Shemwetta, 1997; Chung and Sessions, 2000; Karlsson et al., 2002). In order that some qualitative criteria could be added to decision process of the harvest planning, multi-criteria and qualitative decision making tools such as analytic hierarchy process (AHP) (Engür, 1996; Saaty, 1989) and knowledge based system (Lan, 2001) have been used. Managerial and operational decision making problems make it possible to use a wide range of the OR procedures in forestry (Rönnqvist et al., 2015; Dong et al., 2018), to determine the best course of action with limited resources (Nieuwenhuis, 1989). The literature has illustrated that classic and new generation mathematical models must be developed in order to optimize the operational decisions regarding the planning of wood harvesting (Boyland, 2003; Karlsson et al., 2004; Borges et al., 2014; Jin et al., 2016).

Wood harvesting (cutting, extraction to roadside and loading-hauling to storage) is a dynamic and complex 
process. Furthermore, under the supply and demand uncertainties, the state-owned forest enterprises need advanced supply chain management to improve their competitiveness. Decision makers, especially in the state forest administration, need to manage harvest units, product levels and range, crew and machine assignments, harvesting costs, and operation productivity, along with customer demands, price forecasts and revenues during the operation time horizon. However, forest assets can present added challenges due to market changes, environmental factors, operational constraints, and other considerations. This situation indicates that annual harvest planning is also necessary for Turkish state forestry to be technically applicable, economically profitable, environmentally soundly, and socially acceptable.

Models for operational harvest planning are still largely missing in Turkish forestry. To date, Eker (2020) could not find an application addressing an integrated solution for wood harvest planning with a short-term planning horizon, with yearly or seasonal schedules. Nowadays, the necessity of making operational harvest planning in state-owned forestry has once again emerged on the threshold of developments in the fields of environment, forestry, and technology. However, one of the important handicaps encountered in the planning models is the uncertainty of how planning decisions are optimized and how these decisions will be put into practice.

When a harvest planning requirement for Turkish forestry emerged, the operational harvest planning model (OHARP) developed by Eker (2004) appeared to be a useful approach. The OHARP model was developed to solve the planning problem that considered: a) which harvesting unit/block was to be harvested in each planning season/period, b) which harvesting system was to be used, c) how many harvesting crews were to be employed, d) which state forest storage area would be used, and e) which forest roads were to be used. OHARP used a 12 to 18 months harvesting time frame in a forest district. This planning model incorporated technicaltopographical conditions, economic limitations, environmental restrictions, and social-institutional expectations.

The purpose of this paper is to show, by way of a case study, the theoretical planning methodology and how planners and managers can improve liaison and coordination capability for planning of forest operations and follow-up. The conceptual framework of OHARP methodology is introduced to outline how the planning decision model can be set up for state forestry, which planning steps are to be followed, how operational decisions can be optimized, how model results could be adapted to a real world problem, and what are the probable advantages of the model in solving a test problem.

\section{Methodology}

The planning process of the OHARP methodology is inspired from well-known forest transportation planning, wood supply chain planning, and hierarchical planning procedures. The OHARP model is divided into three modules and each one supports decisions to optimize multi-dimensional objectives for harvest operations: (1) setting up the database system and technical analysis from the harvesting environment and conditions, (2) cost analysis of harvesting systems at the site specific scale, and (3) modeling of operational decisions and the optimization procedures subject to all constraints (Eker, 2004).

\subsection{Database System and Technical Analysis}

In the first module (Figure 1) a spatial database system is designed using GIS, which includes topographical features of the candidate stands for harvesting, road network, and georeferenced information relevant to their attributes. Harvesting compartments or stands to be harvested in the planning horizon are flagged. Information about each stand such as standing tree volume, type of silvicultural prescription, tree species, and background in the previous plan horizon, are added to the spatial database system in GIS software.

By using GIS technology (like ArcGIS), the ground conditions of harvesting stands are classified by functional terrain classification (Samset, 1979; Acar, 1994) according to slope groups to determine appropriate extraction techniques subject to slope limitation. In order to facilitate the selection of primary and secondary transportation systems, forest road density and opening up ratio are calculated by spatial analysis.

Before starting the technical analysis, alternative harvesting technologies owned by forest villagers can be specified. The availability of the cutting, extraction and hauling technologies, the combination of which defines harvesting systems, are determined by topographical conditions, accessibility, and silvicultural intervention in stands. In the GIS environment, transportation boundaries are described for each harvesting stand, where the entire stand boundary is divided into many small harvesting units in terms of topography, skidding direction, and landing location. The skidding distance is calculated for each alternative extraction technique. The real average skidding distance (Erdaş, 1997; Çoban, 2011) for each harvesting unit and stand is estimated with respect to extraction technique, location of forest road, skidding direction, and length of slope. 


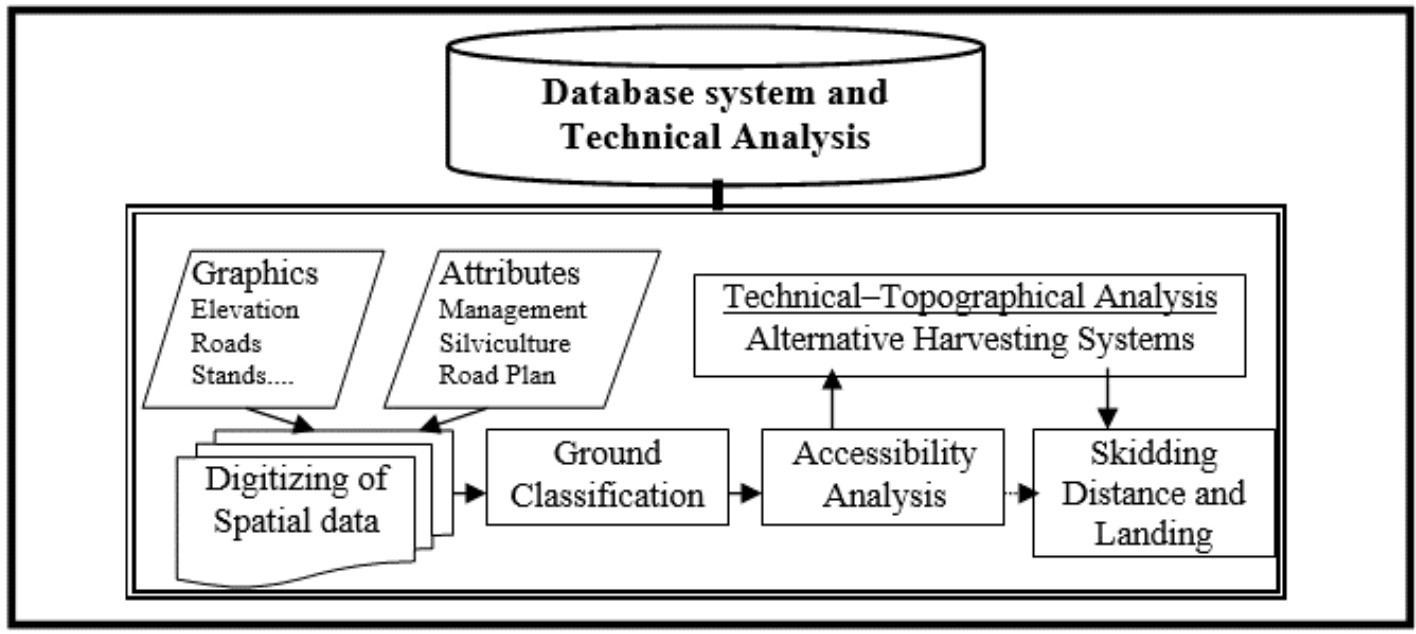

Figure 1. Database system structure and technical analysis process (Eker, 2004)

\subsection{Cost Analysis}

The use of harvesting systems across forest stands and the transport of wood to roadside and storage are arguably the most important decisions at the operational level. The harvest operations including transportation activities ideally need to be conducted with minimal cost, while fulfilling wood supply. The main objective of the OHARP model is to minimize harvesting plus transport cost to deliver the annual allowable cut (AAC). Since the AAC is fixed, the objective of minimizing harvesting plus transport cost is equivalent to minimizing average harvesting unit cost. These costs vary by ground features, stand characteristics, assortment types, harvest volume, harvesting method, time, and harvesting system. The most appropriate harvesting system for the operation is the one with the lowest fixed and variable/operational cost. This stage of calculation of harvesting cost is called the quantitative cost analysis phase (Figure 2). It consists of counting up cutting, felling, bucking, debarking, measuring, skidding, loading, hauling, and unloading cost of per cubic meter of each harvested tree are called harvesting unit cost $\left(\mathrm{TL} / \mathrm{m}^{3}\right)$ that is function of standard working time (hour $/ \mathrm{m}^{3}$ ) and unit price (TL/hour). The standard working time for each harvest technology (human, animal, and machine hours) is abstracted from equations in official regulations which has been renewed recently (GDF, 2020). The unit price is also determined by GDF annually. Costs are estimated at the site-specific level by integrating stand data coming from the GDF database with this calculation procedure.

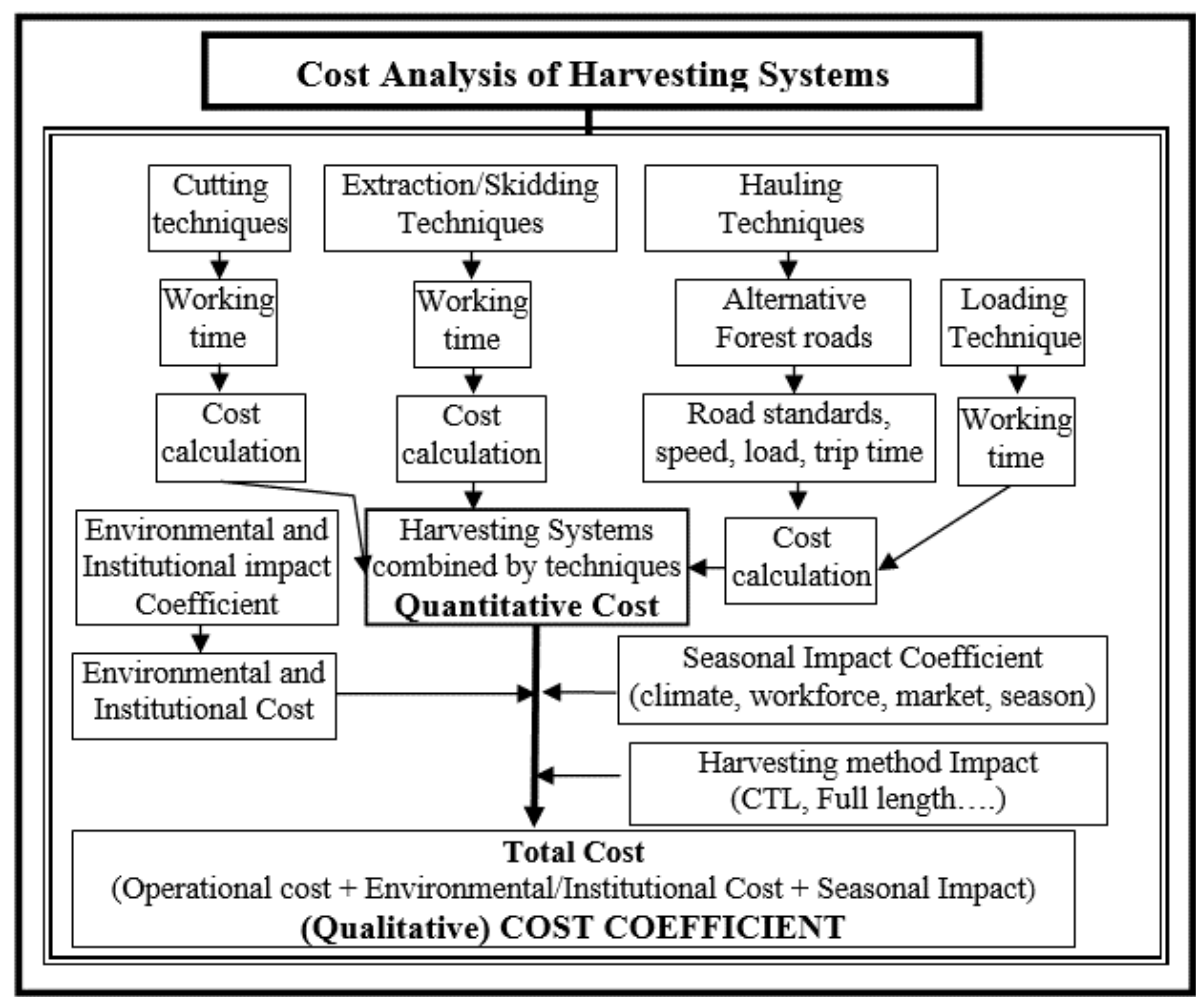

Figure 2. Work flow of harvesting (quantitative and qualitative) cost calculation (Eker, 2004) 
To simplify the calculation procedure and mathematical modeling, the cutting and extraction cost are combined with and inserted into the harvesting unit cost for each harvesting system. The actual average skid distances for each stand are used to calculate the skidding distance of each extraction method and extraction cost for removing of $1 \mathrm{~m}^{3}$ of wood product at this distance. Hauling cost consists of loading, waiting, road trip, and unloading costs. The transportation costs are represented by the distance between the roadside and the state-owned storage, the time taken to travel this distance, the load carried, and the distance and the price corresponding to this activity. Through the digital road network map in GIS databases, an analysis of accessibility from each compartment to alternative storages in the planning area is made. Since the transport time is a function of the speed of the transport vehicles, the transport speeds and transport (load) capacities on the raw/soil, stabilized and asphalt roads are defined and transport times are found. For each road standard, the duration of the trip is found by using the loaded and empty travel times and the distances of the routes.

At this stage, the most economical harvesting system, road route, and storage are quantitatively selected. Unfortunately, it is unknown whether or not this harvesting system is acceptable for environmental and societal criterion, as well. For that reason, a micro level technology selection approach (Engür, 1996; Eker, 2004) is used to compare the harvesting systems for multi-dimensional selection using multi criteria analysis. The Analytical Hierarchy Process (AHP) (Saaty, 1989) is used to determine which criteria is more important in terms of economics, environmental, or social aspect and to obtain a coefficient that will facilitate selection. Additionally, sub-criteria and the indicator set are developed. The result of the AHP methodology is the relative weight vector which can also be manipulated to provide the environmental and institutional impact coefficient including technical and social impacts. This penalty or impact coefficient helps to describe whether the harvesting system is technically applicable, environmentally sound, and institutionally feasible. The environmental and institutional impact (penalty) coefficient of each possible harvesting system is multiplied by the quantitative cost of harvesting system and added to the cost.

Furthermore, seasonal variations in one year can change work productivity, machine usefulness, workforce supply and demand and harvesting cost. Therefore, various criteria such as climate, workforce, market demand, and accessibility are defined to examine performance of each season; there are four three-month harvesting seasons for one planning year.

Harvesting method (cut-to-length or full stem; short or long $\log$ ) is influenced to operational productivity and cost, mechanization level, and workforce. A cost variation ratio (CVR) is determined for each harvesting method. The CVR is multiplied by operational cost of harvesting system to define which harvesting method can be appropriate. Thus, all alternative harvesting systems can be compared quantitatively and qualitatively to select the acceptable one.

\subsection{Modeling of the Operational Decisions}

The major components of OHARP model are to optimize the harvest operations with resource allocation and annual budget. Mathematical modeling applications in forestry are shown in a number of textbooks, for example, Dykstra (1976). The modeling process is summarized in Figure 3.

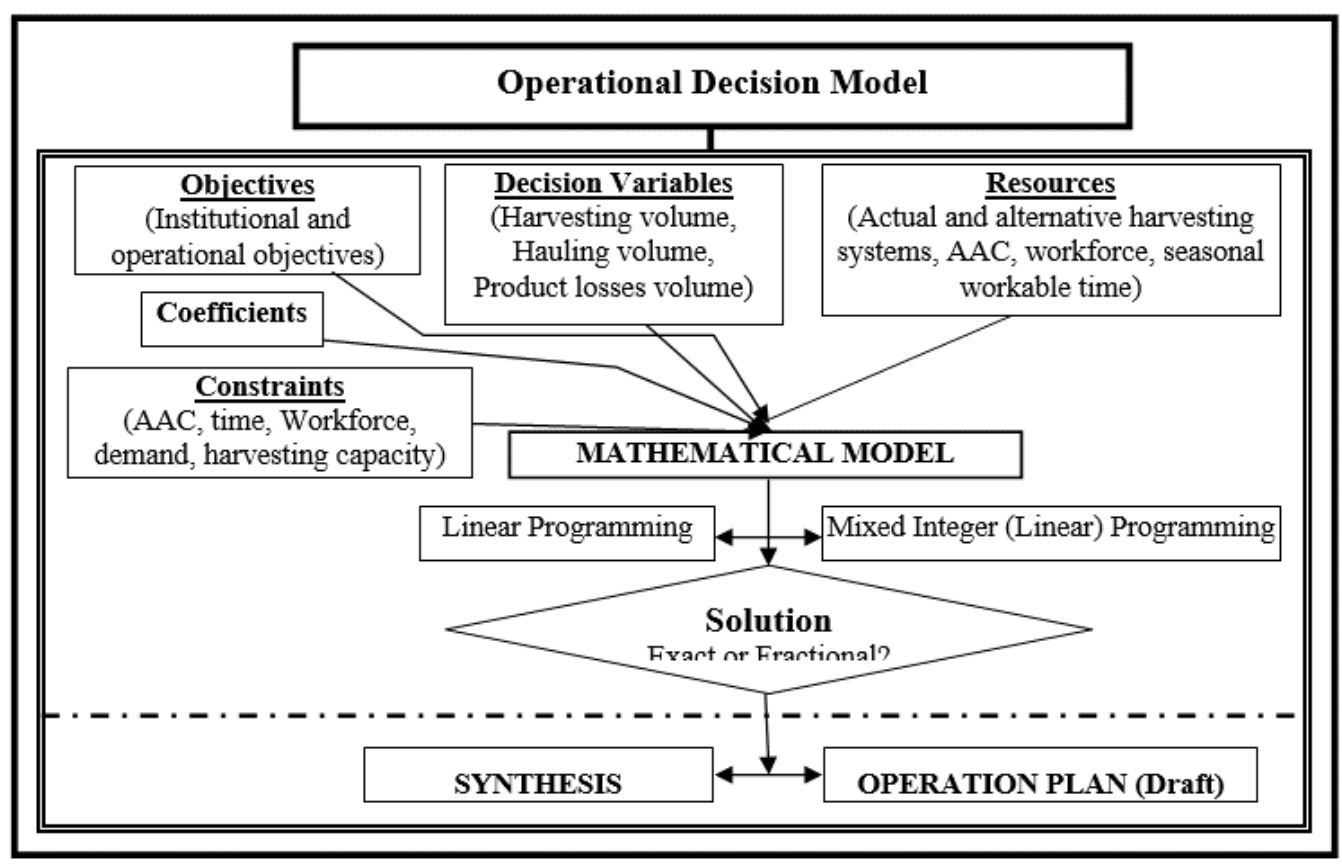

Figure 3. Flowchart about mathematical modeling of operational decisions (Eker, 2004) 
For the mathematical formulation, the planning problem is defined; its components are identified and digitized so that it can be quantitatively solved. The problem here consists of a combination of following questions: (a) which compartment will be harvested, (b) in which period, (c) the amount of wood that needs to be harvested in each period, (d) which harvesting method and system will be used, (e) where the landing locations will be set, (f) which compartment will be opened to operation, (g) through which forest road segment, (h) how much product is to be transported to each storage, (i) the amount of human machine and animal power to be used in harvesting, and (j) the type and number of transport vehicles needed.

The goal is the minimization of harvesting and transportation cost over the one year planning horizon. The cost coefficients to be used in the model are produced by calculating cutting, extraction, and hauling costs. The basic parameters to be included in the model are: (a) the amount of annual allowable harvest in each compartment (tending or final felling), (b) the amount of product to be obtained by any harvesting method, (c) the minimum and maximum amount of wood raw material need in a certain period in each storage, (d) the average unit cost of cutting and extraction operations according to seasonal periods, production method and production systems, (e) the cost of transportation (including loading) of the wood to each storage from each compartment according to the periods, production method and route of the preferred route, (f) capacity of each production system, $(\mathrm{g})$ the length of workable time of each seasonal period of the planning year, and (h) the amount of available manpower (human, animal, machine) in the planning area.

The size of the problem depends upon (a) planning period length (can be taken as 1 year or less), (b) number of periods (seasons, number of days that forest villagers can work, climate effect), (c) number of compartments (tending and regeneration felling), (d) number of harvesting systems (harvesting systems in use that can be used alternatively cutting and extraction), (e) number of harvesting methods/number of varieties of product types (short wood or long wood), (f) number of landing locations, (g) number of storage areas in the forest district, and (h) the number of "routes" that link compartments with storage areas.

Factors that limit the fulfillment of planning objectives are (a) the amount of annual allowable cut in each compartment, (b) workable time span, (c) the amount of available labor (depending on forest villagers voluntary for harvest works) and capacity, and (d) the amount of wood demand needed by the storage areas.

The decision model of OHARP is first set up as a linear programming (LP) model. Special constraints that require semi-continuous or integer variables can be added to the LP model. The objective function and constraint types are described below.
Objective function;

$$
Z_{\text {min }}=\sum\left(P M_{p}+T_{p}\right) \quad \forall p \in P ;(p=1,2,3,4)
$$

Subject to:

- Harvesting volume to be harvested in one compartment or block is limited by AAC volume allowed by forest management and silvicultural plans. $\sum_{b=1}^{B} \sum_{p=1}^{P} \sum_{u=1}^{U} \sum_{s=1}^{S} X_{b p u s} * E T A_{b \in B}-B E T A_{b \in B}=0$

- Total harvesting volume to be harvested in a planning horizon, is equal to total volume of harvesting compartment.

$$
\sum_{b=1}^{B} \text { BETA }_{b}-\text { TOPETA }=0
$$

- Each harvesting compartment has to be harvested in one season of the planning horizon.

$$
\sum_{b=1}^{B} \sum_{p=1}^{P} \sum_{u=1}^{U} \sum_{s=1}^{S} X_{\text {bpus }}{ }^{*} E T A_{b}=1
$$

- Harvesting volume to be harvested in each season is limited by minimum and maximum seasonal limitations.

$$
\operatorname{Min} H Q_{p} \leq H Q_{p} \leq \operatorname{Max} H Q_{p}
$$

- Transported timber volume from each harvesting compartment cannot more than harvested volume in that compartment.

$$
\sum_{b}^{B} \sum_{p}^{P} \sum_{u}^{U} \sum_{s}^{S} X_{b p u s} * E T A_{b \in B}-\sum_{b}^{B} \sum_{p}^{P} \sum_{u}^{U} \sum_{r}^{R} Y_{b p u r} \geq 0
$$

- Total volume to be transported in each season, should be equal or less than harvesting volume in the same season.

$$
\sum_{b}^{B} \sum_{p}^{P} \sum_{u}^{U} \sum_{r}^{R} Y_{b p u r}-\operatorname{TRANSP}_{P} \geq 0
$$

- Transported volume in each season should fit to minimum and maximum limits of the storage, which is a function of the market demands.

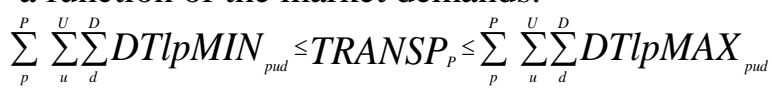

- Harvesting capacity of a harvesting system, depending on productivity, is limited to workable time in one season and number of harvesting system.

$$
\begin{aligned}
& \text { 1) } \sum_{b}^{B} \sum_{p}^{P} \sum_{u}^{U} \sum_{s}^{s} V R M_{\text {bpus }}{ }^{*} X_{\text {bpus }}{ }^{*} E T A_{b}-S_{s} P_{p}=0 \\
& \text { 2) } S_{s} P_{p} \leq A d_{s}{ }^{*} P U_{p}
\end{aligned}
$$

- Transported volume in each season depends on number of trucks to be used in transportation and the length of workable time in each season.

$$
\sum_{b}^{B} \sum_{p}^{P} \sum_{u}^{U} \sum_{r}^{R} V R M_{\text {bpur }} * Y_{\text {bpur }}-K M Y P_{P}=0
$$

$$
K M Y P_{p} \leq A d_{\text {kmyn }} * P U_{p}
$$

- Transportation decision variables have to be positive

$$
Y_{\text {bpur }} \geq 0 \quad \forall b, p, u, r
$$

- Harvesting decision variables that have to be binary [0/1]. If this constraint is removed from the model, MIP model is turn into LP model form. 


$$
X_{\text {bpus }}=\left\{\begin{array}{l}
1 \text { If harvesting of area } b, \text { is harvested during } \\
\text { season } p, \text { by harvesting method } u \text { and system } s \\
0 \text { Otherwise }
\end{array}\right.
$$

In this model, defined sets are;

\section{$B$}

$P$

$U$

$S$

$R$

$D$

$P M p$

$T p$

$X_{\text {bpus }}$

$Y_{\text {bpur }}$

$B E T A_{b}$

TOPETA

$H Q_{p}$

$\operatorname{Min} / \operatorname{MaxH}_{p}$

TRANSP $P_{P}$

DTlpMIN/MAX $X_{\text {pud }}$ : Minimum and maximum market demands during season $p$, for assortment harvested by harvesting method $u$, in the national forest storage $d\left(\mathrm{~m}^{3}\right)$

$S_{s} P_{p} \quad$ : Working time of harvesting system $s$ during season $p$ (hour)

$A d_{s} \quad:$ Total number of utilizable harvesting system $s$

$A d_{k m y n} \quad:$ Total number of utilizable trucks during season $p$

$P U_{p} \quad$ : Working time depending on season $p$ (hour)

$V R M_{\text {bpus }} \quad$ : Operational productivity of the harvesting system $s$, used in compartment $b$ during season $p$ for harvesting method $u$ (hour $/ \mathrm{m}^{3}$ )

$V R M_{\text {bpur }}$

$K M Y P_{p}$
The output of the OHARP model is an operational harvest plan. This plan includes information relating to all harvesting operations during a planning horizon for a current forest district.

\section{Case Study}

An important planning problem for state forest enterprises is how to best utilize their own harvesting resources during the year. This OHARP methodology, supporting the operational decision making process through selection of suitable harvesting system in respect of economical, ecological, ergonomic, and social/institutional criteria, was tested in Turkish Forestry, in Aşağıgökdere Forest Enterprise Chief in the city of Isparta located in south of Turkey.

\subsection{System Description}

Harvesting process included three main operations: felling-processing a tree, extraction tree parts to roadside, and loading-hauling to storage. Harvest operations were in turn classified into final felling and tending. The removed trees were typically used as logs and product range was wide from log to firewood. Industrial harvesting operations were performed using manual and semi-mechanized machines. Tree cutting, delimbing, and bucking were done with chainsaw in the forest stand. Occasionally, debarking operations were executed manually with axe or with a $\log$ wizard mounted to a chainsaw. A harvester (excavator based) was also considered in the case study. Thus, there were three alternatives on cutting techniques (Figure 4).

The alternatives from stump to landing or roadside mostly ranged from manual to mechanized techniques on the steep ground. Use of gravity and human force as rolling, throwing, and sliding/skidding methods were especially preferable by forest villagers. Animal techniques were rarely used in this district. The agricultural tractors for skidding and forwarding the wood products were used in the case study. Both agricultural and forest tractors could be used for extraction with cable logging. Forest skylines are used in mountainous regions of the district. In addition, the log chute system could be available for logging of smalldiameter wood products. Heavy machines such as forwarders and skidders were also available in limited supply. Loading operations in roadside or landing were carried out using grapple loaders or hydraulic cranes. Hauling on secondary forest roads and main roads was done using trucks and trailers.

A number of goals and restrictions were taken into account for the planning of harvesting operations. Information about harvest areas such as geographical location, size, volume, average tree size, skidding distance and terrain accessibility were provided by forest management plan and land survey. The case study area was 16352 hectares and the AAC was $30000 \mathrm{~m}^{3} /$ year. Twelve compartments were to be cut in the planning period; three of which were to be clear-cut and the others partial cut. 


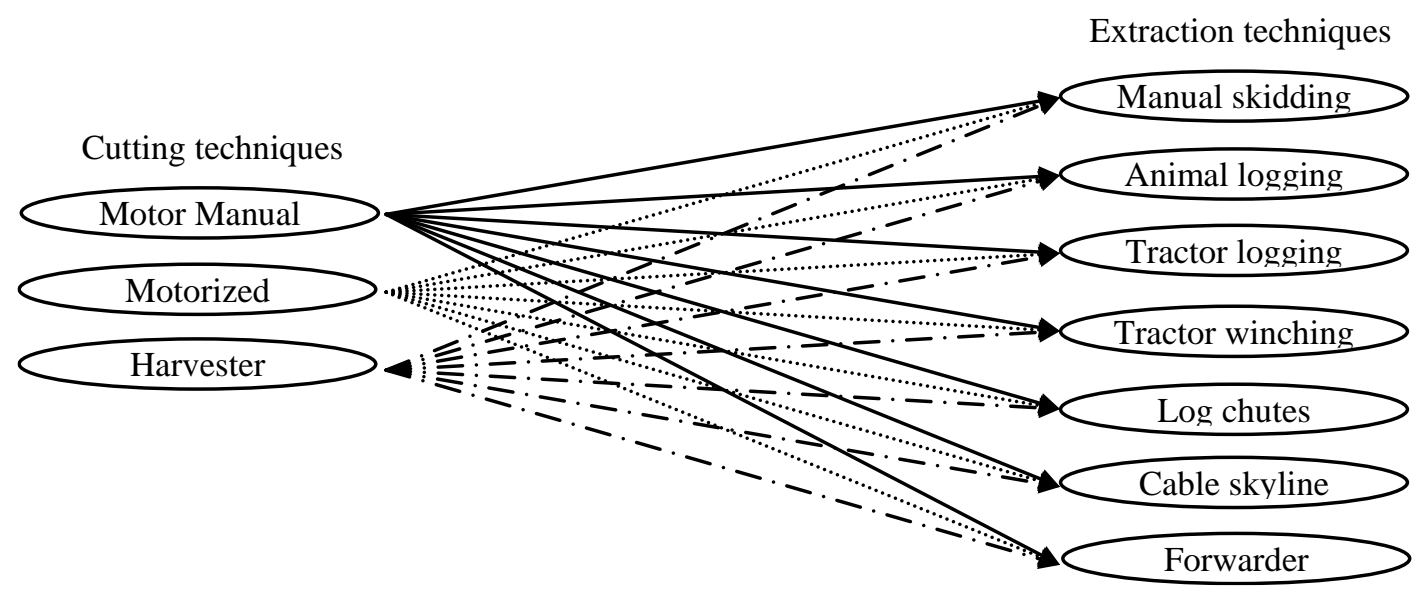

Figure 4. Harvesting system matrix as an alternative paired with cutting and extraction techniques

The harvesting systems typically were operated with teams of four or five family workers. Each crew had chainsaws and other equipment for working 8-h shifts, for 6 days a week. In the planning area, it was determined that 10 harvesting systems were to be used. All forest operations were done by forest villagers; 430 people and 26 crews with 4-5 workers. At least, one fourth of the forest villagers must work in the harvest operations. Ninety chainsaws, 25 draught animals, 25 agricultural tractors could be used in the harvesting and 30 trucks could be used for transportation in this area. Two harvesting methods were used; short and normal log assortment. Two storage areas were used. The harvested products could be transported from different compartments through 2 to 8 routes, changeable for each harvesting compartment, to storage. The problem comprised of 960 decision variables for harvesting and 768 for transportation (Eker, 2004).

\subsection{Solution Procedure}

To solve the test problems, the industrial LINDO solver was used. It could solve the LP model and its extensions by semi-continuous variables, and MIP model by $0 / 1$ binary variables and soft constraints. But, when hard constraints were added to the model, the LINDO MIP solver could not find a solution and a simple heuristic procedure (Weintraub et al., 1994) was used.

\subsection{Results}

The mathematical model, based on linear and mixed integer programming, was solved subject to structural constraints of the planning problem. The test results demonstrated that when the OHARP model was implemented in the test area and compared with the actual cost of the harvest operations realized in this area, a savings of at least $4 \%$ could be achieved by better matching appropriate harvesting systems and methods to the terrain using the OHARP methodology. When operational decisions including resource constraints were optimized, up to a $30 \%$ cost reduction could be achieved in terms of average harvesting and transportation cost (Eker, 2004).
Both LP and MIP models could identify the optimized results. But, the LP presented fractional solutions dividing harvesting seasons, and systems. On the other hand, the MIP offered exact solution sets. It required the harvest of a compartment during one season by one harvesting system and method. Therefore, although the LP model could reach an objective function value about 11 percent lower than the MIP models, the MIP solution satisfied the hard integer constraints and was more real. By selecting the most appropriate harvesting system, season and method, OHARP can enable minimizing of environmental impacts; improving worker health and safety; supplying market demands and satisfying of forest villagers' expectations, socially and politically.

\section{Discussion}

In this article, we propose to introduce a planning model for the annual harvest operations in state-owned forests. Our model aims to minimize the total cost of harvesting activities, including cutting, extraction, and wood transportation costs. At present, there are no annual and operative harvest plans for state-owned forest enterprises (Eker, 2020) that consider the transportation and harvesting program for harvesting compartments. Additionally, the decision-making about harvesting activities are realized manually without an integrated planning concept. OHARP tries to achieve the optimal allocation of resources to harvest forest stands at each period of the planning horizon, providing valuable information to decision makers, in order to increase the efficiency of the harvest operations within a planning concept.

The mathematical formulation of the decisionmaking problem used in this planning methodology is designed as a flexible model that can include not only the coefficients based on quantitative cost data but also qualitative coefficients. Qualitative data is converted to numerical form as a penalty coefficient and can be included in the mathematical model through cost multipliers. Thus, environmental, societal, and institutional criteria is taken into consideration to make a 
decision about which harvesting system is appropriate in terms of spatial and temporal conditions at the site specific level (Eker, 2004). Qualitative cost of each harvesting system may not be a true way to calculate harvesting unit cost, but it can be effectively used in comparison with systems to select the most suitable one. This approach is the most prominent feature of this methodology, and it can be used to make planning decisions in line with economic, ecological and social functions. In the OHARP model, the local workforce can be defined as directly or indirectly restrictive in the mathematical model. That is, the model is drawn up in close collaboration with stakeholders in the relevant region. It can support public participation depending on their workforce (available crew) possibilities and technology capacity for wood harvesting of the local people and interest groups living in the managed forest.

The results of the case study for testing the model based on a real world problem show that the model can be successfully applied to a series of forest conditions. The model can minimize the total costs by choosing the appropriate time for the harvesting compartment, the appropriate harvesting system, appropriate harvesting method, suitable skidding direction to a suitable landing, and road routes to a suitable storage. However, the problem size and the processing time required for the solution, have the potential to substantially grow with the number of compartments/stands and system alternatives. The OHARP model is sensitive to a large number of decision variables such as a large number of compartments. But, in recent years, developing computer technologies on hardware and software and also matrix solvers have significantly reduced solution times.

Temporal and spatial planning decisions requires both a quantitative and qualitative evaluation, so, it is necessary to improve the decision making process with a multi-criteria optimization tool. Consistent and feasible decisions should be made technically, economically, ecologically and socially, rather than decisions based on the rule of thumb and experiences. Therefore, the need for a planning model supporting decision making to achieve optimum goals about wood harvesting is increasing in Turkish forestry. A number of factors have created the appropriate infrastructure for an operational harvest planning model. These include the change in sales methods (standing tree sales at the stump-side), the increasing level of mechanization (increase in the number of harvesters, skidders, tractors and skylines) (Akay et al., 2016), the change in the wood product range, and also the increase in short rotation industrial plantations. Technological improvements (drones, laser scanning and remote sensing tools) and their actual utilization in Turkish forestry for especially high resolution data collection can be made available for operational use and GIS-based inventory. Unfortunately, since the creation of the operational planning model by Eker (2004) a decision support system is still not developed in Turkey, even though various decision support systems have been used for many years (Epstein et al., 1999).

\section{Conclusion}

The proposed operational planning approach to optimize annual wood harvest operations and transportation of the products from stand to storage, takes into account a large number of legislative, technical, economic, environmental, societal, and technological conditions and limitations specific for state-owned Turkish forestry enterprises. A mathematical model for the planning problem was formulated, solved, and analyzed. The proposed model includes the important aspects of the annual planning problem in a forest district having about 15000 ha forest area. The planning model provides optimal allocation of harvesting systems, crews, and trucks. Thus, the case study suggested that today's forestry policies, sustainable forestry objectives, and tactical-level forest management plans can be successfully implemented in Turkish forestry at the operational level.

\section{Ethics Committee Approval: N/A.}

Peer-review: Externally peer-reviewed.

Author Contributions: Concept: M.E.; Design: M.E. and J.S.; Supervision: M.E.; Resources: M.E.; Data Collection: M.E.; Analysis: M.E.; Literature Search: M.E. and J.S.; Writing Manuscript: M.E. and J.S.; Critical Review: M.E. and J.S.

Conflict of Interest: The authors have no conflicts of interest to declare.

Financial Disclosure: The authors declared that this study has received no financial support

Cite this paper as: Eker, M., Sessions, J., 2020. Refocusing on Operational Harvest Planning Model for State-Owned Forestry in Turkey. European Journal of Forest Engineering, 6(2): xx-xx.

\section{References}

Acar, H.H., 1994. Developing Forest Transportation Plans in Mountainous Terrain, Karadeniz Technical University, PhD Thesis, 150 p., Trabzon.

Akay, A.E., Özkan, D., Bilici, E., 2016. Assessing productivity and work safety of a mechanized logging operation. The International Forestry Symposium (IFS 2016). 7-11 December, Kastamonu, Turkey.

Bayoğlu, S., 1972. Forest Transportation and Developing Possibilities in Turkey, İ.Ü. Publication of Forestry Faculty No: 1747/185, İstanbul, 73 p.

Beaudoin, D., Frayret, J.M., LeBel, L., 2008. Hierachical forest management with anticipation: an application to tactical-operational planning integration. Canadian Journal of Forest Research 38 (8):21982211. 
Borges, P., Eid, T., Bergseng, E., 2014. Applying simulated annealing using different methods for the neighborhood search in forest planning problems. Eur. J. Oper. Res. 233: 700-710.

Boyland, M., 2003. Hierarchical planning in forestry. ATLAS SIMFOR Project Technical Report. Department of Forest Science, The University of British Columbia, Vancouver, BC.

Chung, W., Sessions, J., 2000. NETWORK 2000: A Program for Optimizing Large Fixed and Variable Cost Transportation Systems, Proc. of the Eighth Symposium on Systems Analysis in Forest Resources, Arthaud, G.J. (ed.). Sept 28-30, Aspen, Colorado.

Çoban, H.O., 2011. Calculation of average skidding distance on sloping terrain with GIS tools. Turkish Journal of Forestry 12(2):98-103.

Dong, L., Bettinger, P., Qin, H., Liu, Z., 2018. Reflections on the number of independent solutions for forest spatial harvest scheduling problems: A case of simulated annealing. Silva Fenn. 52: 7803.

Dykstra, D.P, 1976. Timber Harvest Layout by Mathematical and Heuristic Programming, PhD Thesis, Oregon State University, 299 p.

Dykstra, D.P., Heinrich, R., 1996. FAO Model Code of Forest Harvesting Practice, FAO Publications, Rome, $85 \mathrm{~s}$.

Eker, M., 2004. Development of Annual Operational Planning Model for Timber Harvesting. PhD Thesis, Karadeniz Technical University, Trabzon, Turkey. $239 \mathrm{p}$.

Eker, M.; Acar, H.H., 2006. Developing an annual harvest operation planning model for Turkish state forestry, Council on Forest Engineering Proceedings The 29th Annual Meeting, July 30-August 2, 363374 pp., Coeur d'Alene-Idaho, USA.

Eker, M., 2020. A Review on Decision Processes for Wood Harvesting in Turkish Forestry. Eur J Forest Eng, 6(1): 41-51

Engür, O.M., 1996. Technology Selection on Forest harvesting and mechanization Possibilities, İstanbul University, $\mathrm{PhD}$ Thesis, İstanbul, $216 \mathrm{p}$.

Epstein, R., Morales, P., Seron, J., Weintraub, A., 1999. Use of OR Systems in the Chilean Forest Industries, Interfaces 29(1): 7-28.

Epstein, R., Weintraub, A., Sapunar, P., Nieto, E., Sessions, J.B., Sessions, J., Bustamante, F., Musante, H., 2006. A Combinatorial Heuristic Approach for Solving Real-Size Machinery Location and Road Design Problems in Forestry Planning. Operations Research 54(6): 1017-1027.

Erdaş, O., 1997. Forest Roads -I, Publication of KTÜ Forestry Faculty, No:187/25, Trabzon, 390 p.

FS,2020. Forestry Statistics, Official Statistics, General Directorate of Forestry. https://www.ogm.gov.tr/ekut uphane/Sayfalar/Istatistikler.Accessed: 25 September 2020.
GDF, 2020. GDF, 2020. Official Communique about Harvesting of Wood-based Forest Products - No:310. General Directorate of Forestry, Ankara, Turkey. https://www.ogm.gov.tr/ekutuphane/Tebligler Accessed: 13 February 2020.

Gunn, A.E., 1991. Some Aspects of Hierarchical Production Planning in Forest Management, Proceedings of the 1991 Symposium on Systems Analysis in Forest Resources, Ed. By Buford, M.A., March 3-6 Charleston, p.53-62

Jin, X., Pukkala, T., Li, F., 2016. Fine-tuning heuristic methods for combinatorial optimization in forest planning. Eur. J. For. Res. 135: 765-779.

Karlsson, J., Rönnqvist, M. ve Bergström, J., 2002. Annual Harvest Planning, Department of Mathematics, Linköping Inst. of Technology, LiTHMAT-R-2002-15, Sweden.

Karlsson, J., Rönnqvist, M., Bergström, J., 2004. An optimization model for annual harvest planning. Canadian Journal of Forest Research, 8: 1747-1754.

Lan, Z., 2001. A Cost Model for Machine Operation in Wood Cutting and Extraction, ECOWOODActivities at the University of Helsiki Partner Number 4, 2001-03-22, Finland

Laroze A., Greber B., 1991. Multi-Level Harvest Planning and Log Merchandising Using GoalProgramming, Proceedings of the 1991 Symposium on Systems Analysis in Forest, Resources, Ed. By Buford, M.A., March 3-6, 199, Charleston, South Carolina p.24-30.

Martell, D.E., Gunn, E., Weintraub, A. 1998. Forest Management Challenges for Operational Researchers, European Operational Research, 104(1): 1-17

Martin, A.J., Sendak, P.E., 1973. Operations Research in Forestry: A Bibliography, USDA Forest Service General Technical Report NE-8. N. Forest Experiment Station Forest Service, $94 \mathrm{p}$.

Nieuwenhuis, M., 1989. Operations Research in Forestry. Irish Forestry, 46(1): 51-58

Oborn, R.M.R.,1996. A Mixed-Integer Programming Model for Tactical Forest Operations Planning, Proceedings of the Meeting on Planning and Implementing Forest Operations to Achieve Sustainable Forests, Ed. by C.R. Blinn, M.A. Thompson, COFE - $19^{\text {th }}$ Annual Meeting and IUFRO, July 29 - August 1., USA, pp.201-212.

Ünver Okan,S., Acar, H. H., 2009. A Damage Prediction Model for Quantity Loss on Skidded Spruce Logs during Ground Base Skidding in North Eastern Turkey. Croatian Journal of Forest Engineering, 30: 59-65.

Reimer, D.R., 1979. An Operational Computer Assisted Forest Engineering System, Proceedings of Symposium on Mountain Logging, Ed. by W. Carson, J. Jorgensen, H. Lysons, IUFRO, 10-14 September, University of Washington. 
Robak, E.W., 1984. Toward a Microcomputer-Based DSS for Planning Forest Operations, Interfaces, 14(5): 105-111.

Rönnqvist; M., Westerlund, A., Carlsson, D., 1999. Extraction of Logs in Forestry Using Operations Research and Geographical Information Systems, Proceedings of the 32. Hawaii International Conference on System Sciences, Hawaii.

Rönnqvist, M., D’Amours, S., Weintraub, A., Jofre, A., Gunn, E., Haight, R.G., Martell, D., Murray, A.T., Romero, C., 2015. Operations research challenges in forestry: 33 open problems. Ann. Oper. Res. 232: 1140.

Saaty, T., 1989. Multicriteria Decision Making: The Analytic Hierarchy Process, RWS Publication, Pittsburg, 219 s.

Samset, I., 1979. The Accessibility of Forest Resources, Proceedings of Symposium on Mountain Logging, Ed. by W. Carson, J. Jorgensen, H. Lysons, IUFRO, 10-14 September, University of Washington.

Schuster, E.G., Leafers, L.A., Thompson, J.E., 1993. A Guide to Computer Based Analytical Tolls for Implementing National Forest Plans, USDA Forest Service, Intermountain Research Station General Technical Report, INT-296.
Sessions, J., Bettinger, P. 2001. Hierarchical planning: pathway to the future? In: Proceedings of the first international precision forestry symposium, $\mathrm{U}$. Washington, Seattle.

Shemwetta, D.T.K., 1997. Comprehensive Timber Harvest Planning for Plantation Forests on Difficult Terrain: Sokoine University of Agriculture Training Forest, Tanzania, $\mathrm{PhD}$ Thesis, Oregon State University, $203 \mathrm{~s}$.

Şafak, İ., Eker, M., Erdem, M., Turan, İ., 2019. Time and motion analysis on cable skidding with agricultural tractors of coniferous logs. Turkish Journal of Forestry Research, 6(1): 58-47.

Weintraub, A., Cholaky, A., 1991. A Hierarchical Approach to Forest Planning, Forest Science 37(2): 439-460

Weintraub, A., Jones, G., Magendzo, A., Meacham, M. ve Kurby, M.; 1994. A Heuristic System to Solve Mixed Integer Forest Planning Models, Operations Research, 42(6): 1010-1024

Weintraub, A., Romero, C., Björndal, T., Epstein, R., 2007. Handbook of Operations Research in Natural Resources. 